\title{
MOVIMENTOS SOCIAIS DE DIREITOS HUMANOS, REGIMES AUTORITÁRIOS E TRANSIÇÃO: ANÁLISE COMPARADA BRASIL E ARGENTINA
}

\section{SOCIAL MOVEMENTS OF HUMAN RIGHTS, AUTHORITARIAN REGIMES AND TRANSITION: COMPARATIVE ANALYSIS BRAZIL AND ARGENTINA}

\author{
Arcénio Francisco Cuco* \\ Junior Ivan Bourscheid ${ }^{* *}$ \\ Rodolfo Silva Marques ${ }^{* * *}$
}

\begin{abstract}
RESUMO: o presente texto tem em vista analisar os fatores que influenciaram a atuação dos movimentos sociais de direitos humanos durante a vigência dos regimes autoritários e as implicações dos mesmos para a atuação dos movimentos no processo de transição democrática no Brasil e na Argentina. No trabalho, procuramos responder à seguinte questão: por que na Argentina houve uma grande mobilização dos movimentos sociais em busca de memória e justiça em relação ao regime da junta militar (1976-1983), diferentemente do que ocorreu no Brasil em relação ao governo militar de 1964-1985? Para estabelecermos uma explicação que permitisse alcançar os objetivos traçados neste trabalho, vimos que era necessário que na análise dos dados fossem conjugadas três categorias de fatores explicativos, que por sua vez facilitariam o estabelecimento de variáveis de comparação entre ambos os países. Dessa conjugação de fatores, apuramos que o processo histórico dos regimes autoritários tem um peso importante na análise da atuação dos movimentos sociais nesses países. Para a coleta de dados que sustenta a nossa base comparativa, privilegiamos a revisão bibliográfica.
\end{abstract}

PALAVRAS-CHAVE: Argentina. Brasil. Movimentos sociais. Regimes autoritários.

ABSTRACT: This article seeks to analyze the factors that influenced the actions of human rights social movements during the authoritarian regimes, as well as in the process of democratic transition in Brazil and Argentina. At the same time, we seek to answer the following question: Why in Argentina there was a great mobilization of social movements struggling for memory and justice related to the regime of the military government (1976-1983), and in Brazil there was not much to the military government of 1964-1985? To establish an explanation that would help us to

\footnotetext{
* Doutorando em Ciência Política pela UFRGS. Mestre em Ciências Criminais pela Pontifícia Universidade Católica do Rio Grande do Sul. Integrante do Grupo de Pesquisa Direito à Verdade e à Memória e Justiça de Transição e do Grupo de Pesquisa em Criminologia (GEPCRIM). Membro do Conselho Editorial da Revista Direito \& Inovação do Curso de Direito da URI/FW. E-mail: arcuco@yahoo.com.br

** Mestrando do Programa de Pós-Graduação em Ciência Política da Universidade Federal do Rio Grande do Sul, Bacharel em Relações Internacionais pela Universidade Federal de Santa Maria (2014), Pesquisador membro do Núcleo de Pesquisas em Relações Internacionais de Santa Maria, e $2^{\circ}$ Secretário do Centro de Integração Latino-Americana. Email: junior_bourscheid@hotmail.com

Doutorando em Ciência Política pela UFRGS. Mestre em Ciência Política pela Universidade Federal do Pará (UFPA). Especialista em Marketing pela Fundação Getúlio Vargas. Bacharel em Comunicação Social pela Universidade da Amazônia (UNAMA). Servidor Público do Tribunal de Justiça do Estado do Pará. Professor Universitário da Universidade da Amazônia (UNAMA) e da Faculdade de Estudos Avançados do Pará (FEAPA). Email: rodolfo.smarques@gmail.com
} 
achieve the objectives outlined in this paper, we saw that it was necessary to sustain the data by combining three categories of explanatory factors, which in turn would facilitate the establishment of comparison variables between both countries. From this combination of factors, we found that the historical process of authoritarian regimes is an important factor to analyze the activity of social movements in both countries. To collect data that supports our comparative basis, we appeal to the literature review.

KEYWORDS: Argentina. Authoritarian regimes. Brazil. Social movements.

\section{INTRODUÇÃO}

A América Latina viveu nas décadas de 1960 e 1970 a ascensão de vários regimes autoritários que chegaram ao poder por via de golpes de Estado sucessivos. Para Comblin (1978), a utilização da repressão, sob o auspício do combate ao expansionismo do comunismo, para garantir a obediência popular e a neutralização do surgimento de qualquer que fosse a oposição a esses regimes foi a principal característica dos regimes autoritários.

Assim, tanto no Brasil quanto na Argentina foram vistas violações massivas dos direitos humanos, com perseguições e mortes ligadas aos processos de luta contra um suposto inimigo interno. Ou seja, os regimes autoritários nos dois países tentaram eliminar da esfera pública qualquer elemento contestatório ao poder vigente. Mas nem com isso foi possível acabar com a mobilização dos movimentos sociais que buscavam justiça ante os crimes e violência impostos por esses regimes, quer no seu auge, quer durante o período de transição. É com base neste contexto de mobilização dos movimentos sociais em busca de memória, justiça e reparação que elabora-se o presente artigo.

Neste trabalho, procuramos responder à seguinte questão: por que na Argentina houve uma considerável mobilização dos movimentos sociais em busca de memória e justiça em relação ao regime da junta militar (1976-1983), de modo diverso ao que ocorreu no Brasil quanto ao governo militar de 1964-1985?

A resposta é que, embora ambos os países tenham passado por regimes autoritários, aspectos conjunturais ditaram a intensidade da atuação dos movimentos sociais em cada país. É a partir deste ponto (como poder-se-á observar mais adiante) que estabelecemos categorias de fatores, assim como variáveis que condicionaram as diferenças entre ambos os países no que tange à atuação dos movimentos sociais de direitos humanos. Analisamos três categorias de fatores: conjunturais, estruturais e organizacionais. Os fatores conjunturais consistiram na visita da Comissão Interamericana de Direitos Humanos à Argentina em 1979 e na aprovação da Lei de Anistia no Brasil no mesmo ano; os fatores estruturais estão ligados à relação entre os regimes de 
exceção, a sociedade e os movimentos de direitos humanos, bem como ao processo de transição do regime de exceção e do retorno ao governo civil; e, finalmente, os fatores organizacionais são referentes à forma como os movimentos sociais se estabeleceram nos dois países. E, para cada categoria de fatores, é elencado um certo conjunto de variáveis que possibilitam entender o nosso objeto.

O nosso objetivo é analisar os fatores que influenciaram a atuação dos movimentos sociais de direitos humanos durante a vigência dos regimes autoritários, e as implicações que esses fatores postaram aos movimentos de direitos humanos no processo de transição democrática no Brasil e na Argentina. Não nos propomos debater as instituições (Comissões da Verdade) e mecanismos de justiça (direito à reparação, responsabilização dos perpetradores dos abusos cometidos no passado) surgidos após o retorno à democracia em ambos os países, sob influência da atuação dos movimentos de direitos humanos.

Para a coleta de dados que sustentam a nossa base comparativa, privilegiamos a revisão bibliográfica. A partir da análise de referencial bibliográfico referente aos movimentos de direitos humanos argentinos e brasileiros, alguns aspectos tornaram-se recorrentes, o que possibilitou elencar, num âmbito mais específico, algumas variáveis comparativas, e a partir daí criar categorias de fatores de explicação para o problema proposto. Com isso, logramos estabelecer uma relação, entre os fatores e as variáveis, e as implicações desses elementos para o objeto de estudo.

\section{ANÁLISE COMPARATIVA DA ATUAÇÃO DOS MOVIMENTOS DE DIREITOS HUMANOS NA ARGENTINA E NO BRASIL}

Ao se considerar um cenário comparado entre as características de Brasil e Argentina e analisando algumas das contribuições sobre a participação dos movimentos de direitos humanos na transição democrática nos dois países, podemos elencar três categorias de fatores que implicam a diferença entre a experiência dos movimentos de direitos humanos na Argentina e no Brasil: 1) Fatores Conjunturais, que consistem em eventos exógenos aos movimentos, com papel preponderante no fomento da mobilização ou inércia social; 2) Fatores Estruturais, ligados à relação entre os regimes de exceção e a sociedade e os movimentos de direitos humanos, bem como o processo de transição do regime de exceção para o retorno ao governo civil; e 3) Fatores Organizacionais, referentes à forma como os movimentos sociais de direitos humanos se estabeleceram e se desenvolveram nos dois países.

Cada um desses fatores abarca determinado tipo de variáveis comparativas que auxiliam na compreensão das diferenças entre os dois casos estudados. No primeiro conjunto de fatores 
encontramos a variável eventos exógenos, com papel preponderante no fomento ou não da mobilização social. No segundo conjunto, analisamos sete variáveis comparativas: estratégia do regime contra o comunismo; processo de modernização social e cultural; mecanismos de censura; resposta institucional às demandas dos movimentos de direitos humanos; papel dos líderes do antigo regime na transição; tratamento governamental aos movimentos de direitos humanos no final do regime autoritário; participação da sociedade no final do regime. E, no terceiro conjunto, as variáveis encontradas são: transposição de demandas privadas ao espaço público e estruturação prévia dos movimentos de direitos humanos.

Nesse sentido, entendemos como fatores conjunturais aqueles que são relativos a um determinado contexto específico, que não envolvem nem a evolução histórica dos movimentos de direitos humanos, tampouco a estruturação do regime militar; por exemplo, eventos específicos como a visita da Comissão Interamericana de Direitos Humanos à Argentina e a Lei de Anistia brasileira, ambos ocorridos em 1979. Como fatores estruturais, consideramos os ligados à estruturação dos regimes de exceção nas variáveis que impactam diretamente em seu relacionamento com a sociedade. Os fatores organizacionais, por sua vez, referem-se a elementos da dinâmica interna dos movimentos de direitos humanos, na busca da criação de uma identidade comum, capaz de articular práticas de protesto social.

Em seguida, analisamos cada conjunto de fatores, com suas respectivas variáveis, de modo que possibilite a compreensão das diferenças na atuação dos movimentos de direitos humanos nos dois países, como indica a tabela a seguir: 
Tabela 1. Relação categoria de fatores \& Variáveis

\begin{tabular}{|c|c|c|}
\hline FATORES & VARIÁVEL & Relação fatores \& Variáveis \\
\hline $\begin{array}{l}\text { 1.1 Fatores } \\
\text { conjunturais }\end{array}$ & 1.1.1 Eventos exógenos & $\begin{array}{l}\text { Seu papel no fomento da } \\
\text { mobilização ou inércia social. }\end{array}$ \\
\hline \multirow{7}{*}{$\begin{array}{l}1.2 \text { Fatores } \\
\text { estruturais }\end{array}$} & $\begin{array}{c}\text { 1.2.1 Estratégia do regime contra } 0 \\
\text { comunismo }\end{array}$ & \multirow{7}{*}{$\begin{array}{l}\text { Relação entre os regimes de exceção } \\
\text { com a sociedade e os movimentos de } \\
\text { direitos humanos, bem como o } \\
\text { processo de transição do regime de } \\
\text { exceção para o retorno ao governo } \\
\text { civil. }\end{array}$} \\
\hline & $\begin{array}{c}\text { 1.2.2 Processo de modernização } \\
\text { social e cultural }\end{array}$ & \\
\hline & 1.2.3 Mecanismos de censura & \\
\hline & $\begin{array}{c}\text { 1.2.4 Resposta institucional às } \\
\text { demandas dos movimentos de } \\
\text { direitos humanos }\end{array}$ & \\
\hline & $\begin{array}{l}\text { 1.2.5 Papel dos líderes do antigo } \\
\text { regime na transição }\end{array}$ & \\
\hline & $\begin{array}{c}\text { 1.2.6 Tratamento governamental } \\
\text { aos movimentos de direitos } \\
\text { humanos no final do regime } \\
\text { autoritário }\end{array}$ & \\
\hline & $\begin{array}{l}\text { 1.2.7 Participação da sociedade no } \\
\text { final do regime }\end{array}$ & \\
\hline \multirow{2}{*}{$\begin{array}{c}\text { 1.3 Fatores } \\
\text { organizacionais }\end{array}$} & $\begin{array}{c}\text { 1.3.1 Transposição de demandas } \\
\text { privadas ao espaço público }\end{array}$ & \multirow{2}{*}{$\begin{array}{l}\text { A forma como os movimentos } \\
\text { sociais de direitos humanos se } \\
\text { estabeleceram e desenvolveram nos } \\
\text { dois países. }\end{array}$} \\
\hline & $\begin{array}{c}\text { 1.3.2 Estruturação prévia dos } \\
\text { movimentos }\end{array}$ & \\
\hline
\end{tabular}

Fonte: elaboração dos autores

\subsection{FATORES CONJUNTURAIS}

Um primeiro elemento considerado no estudo dos movimentos de direitos humanos argentinos e brasileiros, e que por sua vez consiste na variável comparativa dos fatores conjunturais, é o impacto de eventos exógenos, que implicaram a criação ou encerramento de oportunidades de atuação desses movimentos diante da sociedade. Constatamos que, no caso argentino, a visita da Comissão Interamericana de Direitos Humanos (CIDH), em 1979, criou novos espaços para a atuação dos movimentos de direitos humanos, enquanto, no caso brasileiro, temos a influência da Lei de Anistia, de 1979, para a mitigação do debate acerca das violações de direitos humanos, transformando-se num aparente pacto de silêncio acerca da temática. Apreciaremos, em seguida, como essa variável comportou-se em cada um dos casos estudados. 


\subsubsection{A visita da CIDH à Argentina e a Lei de Anistia no Brasil}

A partir de 1978, o Processo ${ }^{1}$ intensificou sua campanha para apaziguar os ânimos externos quanto às denúncias de violações de direitos humanos, observando-se a diminuição do número de detidos que estavam à disposição do Poder Executivo Nacional, bem como a diminuição acentuada das denúncias de sequestros, buscando-se assim estabelecer o encerramento do período da "guerra” (os dois primeiros anos do Processo) e o início do período da "paz” (NOVARO; PALERMO, 2006).

Desse modo, atendendo às crescentes pressões do governo estadunidense, e visando à melhoria da imagem internacional do Processo, o presidente Jorge Videla oficializou o convite para a visita da CIDH - organismo da Organização dos Estados Americanos - em dezembro de 1978, constando no mesmo documento que a missão não teria restrições quanto à sua atuação (excetuando-se a entrada nas bases militares).

A delegação enviada pela CIDH chegou a Buenos Aires no dia 6 de setembro de 1979. Novaro e Palermo (2006, p. 294) ressaltam a intensificação do trabalho das organizações de direitos humanos que, desde o surgimento da possibilidade da concretização da visita da CIDH, “comenzaron a trabajar para que la misión recibiera el mayor número posible de testimonios”.

De fato, o saldo deixado pela visita da CIDH foi positivo aos movimentos de direitos humanos. Para Novaro e Palermo (2006), o evento possibilitou a penetração dos reclamos dos familiares de perseguidos na sociedade. A aglomeração de pessoas em frente ao escritório aberto para a missão em Buenos Aires, repetindo-se em Córdoba e Tucumán, culminou no acolhimento de 5.580 denúncias de desaparecimentos, superando qualquer cálculo prévio. Ocorre, a partir de então, uma difusão de informação cada vez mais abundante e precisa sobre o tema das violações. E é essa expansão informativa que suscitará, entre 1980 e 1981, uma batalha pelas consciências da ampla gama da população com uma posição neutra quanto às violações de direitos humanos (nem apoiadores nem afetados pela repressão do regime).

No caso brasileiro, também encontramos um evento exógeno aos movimentos de direitos humanos que se apresenta como elemento relevante para a análise das possibilidades de desenvolvimento desses movimentos. A crescente mobilização social causada pelo debate acerca da aprovação da Anistia pelo Congresso Nacional começou focada na violação dos direitos humanos, mas acabou por priorizar outras questões relativas à participação da sociedade nos processos políticos nacionais, mudando o foco para as demandas por abertura política.

\footnotetext{
${ }^{1}$ Forma como era conhecido o regime instalado pela junta militar que tomou o poder em 24 de março de 1976 , autodenominando-se Proceso de Reorganización Nacional.
} 
A proposta da Anistia por parte do governo tinha um objetivo similar ao do Processo argentino de convite à CIDH para efetuar sua visita - qual seja, a pacificação da Nação.

A ideia proposta na Anistia era justamente a de pacificação da nação, sendo entendida por muitos como um momento em que seria necessário esquecer o passado para projetar o futuro. Nesse sentido, as questões que diziam respeito aos anos de ditadura deveriam ser (mesmo que momentaneamente) esquecidas (BARREIRA; GONÇALVES, 2010, p. 73).

Nesse sentido, González (1994, p. 9) afirma que a Lei de Anistia "tenta colocar um fim na discussão sobre a punição das violações, constituindo-se na 'Lei do Ponto Final’ brasileira. Na política institucional a questão dos direitos humanos acaba ficando em segundo plano”. Gonçalves (2006, p. 52) aponta para as mobilizações em prol da anistia como um turning point da participação social para a transição do regime, pois "preconizava [a] busca pela liberdade de expressão, liberdades políticas e democracia”, contudo, sem apontar para a questão dos direitos humanos como pauta central para a transição.

Por conseguinte, consideramos a visita da CIDH como um evento que fomentou a mobilização social na Argentina, criando espaços para a atuação dos movimentos de direitos humanos na sociedade. Enquanto, no Brasil, a Lei de Anistia representou a conformação de uma espécie de inércia social, ou seja, acabou servindo como um elemento pacificador buscando a superação da atuação do regime, preparando o terreno para a transição política futura - a Lei de Anistia coloca a questão das violações de direitos humanos em segundo plano, criando-se uma cumplicidade entre o governo e a sociedade.

\subsection{FATORES ESTRUTURAIS}

Como anteriormente referimos, este conjunto de fatores apresenta uma série de variáveis comparativas para os dois países, permitindo compreender as distinções entre os regimes de exceção argentino e brasileiro quanto ao modo como se relacionavam com a sociedade, especialmente com os afetados pela repressão dos aparatos de segurança. A análise dessas variáveis permitirá concluir se elas influenciaram ou não na mobilização social por direitos humanos. Passamos à análise comparada das sete variáveis apresentadas nesse conjunto de fatores.

\subsubsection{A estratégia do regime contra o comunismo}

Para analisarmos essa variável, partimos do pressuposto de que ambos os regimes instalaram-se como uma resposta ao suposto avanço do comunismo internacional, e assim tentamos 
perceber quais as estratégias utilizadas para se lograr tal objetivo e quais as implicações dessas estratégias para o restante da sociedade.

Nesse sentido, entende-se que no caso argentino a estratégia empregada foi a de combate ao comunismo guerrilheiro, subversivo, que havia se expandido durante o início da década de 1970 e representava uma ameaça potencial ao modelo político-ideológico do Processo ${ }^{2}$. Assim, o que se observou foi a instalação da guerra antissubversiva que buscava o "fechamento definitivo de um ciclo histórico", a "reorganização da Nação dada a anarquia e a dissolução que se vivia” (MALLIMACI, 2006).

É nesse contexto que se legitima a doutrina da "guerra justa” (NOVARO; PALERMO, 2006), amplamente defendida por militares e religiosos, que viam na guerra antissubversiva a única forma de livrar o País do "mal comunista” (NOVARO; PALERMO, 2006). Contudo, tal doutrina ultrapassava o mero combate à guerrilha e conformava-se num modo maniqueísta de compreender a sociedade, em que todo opositor era visto como pertencente ao grupo antagônico, comunista.

No se trataba de responder a un adversario armado, que comenzó a operar cuando el dogma del exterminio ya había echado raíces castrenses, sino a todo aquello que se opusiera a un presunto plan divino, cuya enumeración no reconocía límites. Esto explica el amplio espectro elegido como blanco a batir (VERBITSKY, 2013, p. 24).

Com isso, argumenta Steinke (2011, p. 3), as forças armadas argentinas sustentavam um discurso que focava elementos como a extirpação, erradicação ou reestruturação, preocupando-se com o elevado número de militantes de esquerda no País, o que, por sua vez, "fez com que se estruturasse um aparato repressivo sem precedentes na Argentina”.

Já no caso brasileiro, a estratégia utilizada conformou-se na contenção do comunismo e, em última instância, foi uma estratégia de prevenção. Pereira (2010) divide a repressão no Brasil nesse período em duas ondas. A primeira, à época do golpe, focava em pessoas suspeitas de pertencerem ao Partido Comunista Brasileiro e nos conhecidos apoiadores do governo anterior ${ }^{3}$. A

\footnotetext{
${ }^{2}$ Na análise efetuada por Novaro e Palermo (op. cit., p. 68) é apresentada a evolução das duas principais organizações guerrilheiras do período, o Ejército Revolucionario del Pueblo (ERP) e os Montoneros, que a partir de 1975 “decidieron intensificar la ‘militarización’ de sus cuadros y militantes y de sus acciones”. O ERP chegou a instalar uma guerrilha rural em Tucumán, desencadeando o esboço do aparato repressivo do Processo, por meio do Operativo Independencia, mobilizando cerca de 5.000 militares para o combate à guerrilha. Contudo, os autores questionam a percepção dos militares do grau da ameaça do comunismo guerrilheiro, apreciando a discrepância de números apresentados por estudiosos dos movimentos e pelos militares, os primeiros considerando a existência de, no máximo, 5.000 guerrilheiros na Argentina, enquanto os segundos apresentavam em documentos oficiais a cifra de 15.000 guerrilheiros, não existindo em ambos os contextos quaisquer fontes confiáveis para tais afirmações.

${ }^{3}$ Entre 1961 e 1964 o País fora presidido por João Goulart (“Jango”), que assumiu o cargo após a renúncia do presidente Jânio Quadros. A partir de 1963, e principalmente em 1964, Jango centrou sua plataforma de governo nas reformas de base, observadas por setores conservadores como uma ameaça para a estabilidade político-institucional brasileira. Com a manutenção do projeto das reformas de base como força motriz do governo Jango, operou-se a reação militar, com o
} 
segunda onda emergiu no final dos anos sessenta, como uma reação ao surgimento de uma esquerda armada. Segundo o autor, “essa repressão foi mais brutal, mais generalizada e mais centralizada que a onda anterior, mas ainda foi bastante seletiva, uma vez que a esquerda armada era pequena e desprovida de apoio de massa” (PEREIRA, 2010, p. 56).

Em contraposição ao caso argentino, no Brasil a repressão mais generalizada foi sendo utilizada paulatinamente, como forma de contenção à esquerda armada que começava a atuar em algumas regiões do País. Se na Argentina o Processo se instalou concomitantemente com o aprofundamento da guerra antissubversiva, no Brasil a tônica da ação se deu com a lógica preventiva, fator que poderia explicar a repressão relativamente seletiva encontrada por Pereira.

Considerando o comportamento da variável nos dois casos, percebemos que na Argentina a estratégia de combate ao comunismo, partindo de uma doutrina maniqueísta de divisão da sociedade entre aliados e inimigos, em que todo inimigo deveria ser extirpado da sociedade, fez com que a repressão tivesse impacto mais generalizado. Desta forma, a partir do momento em que a sociedade começa a sentir o impacto dessa doutrina maniqueísta, passando a ter, com a visita da CIDH, acesso a informações, começa a perceber a importância da mobilização social para a revisão da situação criada pela repressão da doutrina do regime. No Brasil, entretanto, a estratégia de prevenção ao comunismo pautou-se por uma repressão mais seletiva, restringindo o impacto social da estratégia aos ambientes específicos dos afetados, não havendo oportunidade para que os movimentos de direitos humanos suscitassem o apelo de suas demandas no âmbito social mais geral.

\subsubsection{O processo de modernização social e cultural}

A análise desta variável se refere ao modo como o regime de exceção conseguiu capitalizar os avanços do processo de modernização e dinamização social e cultural, restringindo os espaços contestatórios. Neste sentido, avaliamos como os regimes se beneficiaram dos avanços econômicos para sua legitimação na sociedade.

Ao se considerar o caso argentino, observa-se que o período de maior dinamismo da modernização social e cultural compreende os anos de 1966-1973. Todavia, o governo militar então vigente não logrou capitalizar os avanços na esfera econômica para neutralizar o conflito nas arenas social e cultural, sendo a oposição a maior beneficiada (NOVARO; PALERMO, 2006).

Quanto ao regime de 1976-1983, este não pôde beneficiar-se dos parcos avanços do período. A modernização desse período caracterizou-se por ser “pálida, carente de profundidade e 
dinamismo"; foram os chamados anos intermináveis do regime da junta militar (NOVARO; PALERMO, 2006, p. 354-6). Com o colapso do modelo, advindo da crise econômica do início dos anos 1980, os setores beneficiados não se sentiram em dívida com os artífices do modelo econômico que sustentavam os avanços relativos logrados.

Um quadro distinto pode ser observado no caso brasileiro, no qual o endurecimento do regime - a partir de 1969, principalmente - concatenou-se com o desenvolvimento capitalista, no período do milagre econômico brasileiro. Isso trouxe apoio da população ao regime, por parte dos setores beneficiados, que assim passaram a temer o retrocesso da situação nacional, pois poderia interferir diretamente em sua situação pessoal. Haveria uma forma de compromisso dos setores beneficiados com a política econômica dos militares, especialmente com o primeiro Plano Nacional de Desenvolvimento (PND) (NOVARO; PALERMO, 2006).

Assim, o que diferencia as possibilidades de capitalização da situação econômica - e suas implicações sociais e culturais - por ambos os regimes reside na constância dos avanços. No caso brasileiro, o período de 1968-1973 apresentou resultados econômicos inéditos, com uma taxa média de crescimento acima de $10 \%$ ao ano e crescimento da produção industrial e do consumo, impulsionados principalmente pelo programa econômico do ministro da economia Antônio Delfim Netto, por meio do PND (GREMAUD; VASCONCELLOS; TONETO JR, 2007). Desse modo, o governo Médici logrou beneficiar-se politicamente desses avanços, legando para Ernesto Geisel seu sucessor - tais benefícios. No caso argentino, porém, além de um desempenho de menor eficiência em números absolutos, baseado em resultados de escasso dinamismo, outro aspecto a se ressaltar é a volatilidade econômica do período, que, a partir de 1980-1981, fez a economia entrar em colapso, não se conseguindo fornecer benefícios políticos relevantes para seus artífices (NOVARO; PALERMO, 2006).

O impacto de ambos os cenários para a atuação dos movimentos de direitos humanos é analisado quanto à legitimação do regime lograda com suas políticas econômicas. Enquanto no Brasil o regime militar, por meio do “milagre econômico”, conseguia concatenar avanço econômico com o aprofundamento da repressão, na Argentina o avanço econômico mostrou-se menos eficiente, não conseguindo acarretar o tipo de legitimação observado no caso brasileiro. Nesse sentido, no Brasil o regime militar era considerado o propulsor do crescimento econômico, possibilitando sua legitimação e o apoio dos beneficiados, enquanto na Argentina não o era, alimentando a contestação ao regime ante a observância de resultados econômicos negativos. 


\subsubsection{Mecanismos de censura}

No tocante a esta variável, sua apreciação visa vincular o modo como o regime mitigava a contestação pública com as possibilidades de atuação dos movimentos de direitos humanos, observando-se que a existência de um processo burocratizado no Brasil fornecia uma faceta de legitimidade à censura de determinados grupos e demandas, enquanto na Argentina a censura generalizada baseada no temor difundido pela repressão acabava fomentando determinados modos de atuação e demandas que começavam a ser acolhidas em grupos crescentes da população.

Na Argentina, podemos observar a existência de mecanismos de autocensura da imprensa, tanto por parte dos apoiadores dos métodos adotados pelo Processo quanto por aqueles que temiam serem alvos desses métodos (NOVARO; PALERMO, 2006). Aqueles que, mesmo assim, faziam oposição aberta ao regime passavam a ser tratados como inimigos pela doutrina da guerra justa. Assim, considerando-se as denúncias recebidas pela Comissão Nacional sobre o Desaparecimento de Pessoas na Argentina (CONADEP), 1,6\% dos detidos e desaparecidos é composto por jornalistas, sendo este um dos grupos menos afetados pela repressão, apontando para certa efetividade dos mecanismos de autocensura da própria imprensa (CONADEP, 1984).

Por outro lado, no caso brasileiro a censura manteve a lógica geral do regime de busca de legitimidade perante a sociedade com mecanismos focados no aspecto de legalidade. Podemos observar um processo de burocratização, institucionalização e profissionalização da censura, principalmente após a promulgação do Ato Institucional Número 5, com órgãos públicos de censura, como o Conselho Superior de Censura e o Conselho Nacional de Telecomunicações (PEREIRA, 2010). Assim, no Brasil era preciso analisar “caso por caso” as violações da Lei de Segurança Nacional no concernente à atuação dos jornalistas, passando a imagem pública de que o regime apenas condenava os violadores da lei (NOVARO; PALERMO, 2006).

Em suma, no caso do Brasil, o regime censurava opiniões críticas ao governo e aos atos institucionais, bem como tudo o que contrariava os interesses governamentais, na busca da construção de uma imagem positiva da nação: “colocando censores nas redações ou enviando recomendações do que não deveria ser noticiado para muitos jornais de todo o Brasil, os militares buscaram criar a ideia de harmonia social” (SAMWAYS, 2008, p. 1).

Como consequência desses dois métodos de censura para a atuação dos movimentos de direitos humanos, vemos que na Argentina a censura baseava-se na difusão generalizada do temor em contestar as políticas do Processo, enquanto no Brasil a institucionalização da censura fornecia a ela uma faceta legalista. Na Argentina, quanto mais o Processo dava mostras de suas limitações em se manter no poder, mais os movimentos de direitos humanos ganhavam espaço na sociedade, 
contestando-se os métodos de repressão que eram censurados anteriormente, dado o temor de sofrer a mesma sorte de violações, ao passo que, no caso brasileiro, a censura e a repressão eram vistas por outro enfoque, dada a preocupação do regime com a aparência de legalidade, de certa forma dificultando a atuação dos movimentos de direitos humanos. É neste sentido que se considera que “no Brasil, [...] durante todo o período do regime militar, foi mantida a aparência de uma esfera pública em que a contestação era permitida” (PEREIRA, 2010, p. 138); ou seja, a repressão e a censura eram medidas necessárias para a proteção e a segurança dos cidadãos cumpridores da lei, contra os “terroristas perigosos, subversivos, comunistas e seus cúmplices” (PEREIRA, 2010, p. 138).

\subsubsection{Resposta institucional às demandas dos movimentos de direitos humanos}

A apreciação desta variável busca apresentar elementos que permitam observar as implicações da forma como os regimes respondiam institucionalmente às demandas dos movimentos de direitos humanos, e como essa resposta fomenta ou não a mobilização social, buscando canais alternativos para o acolhimento dessas demandas.

Analisando alguns estudos acerca de movimentos de afetados na Argentina, percebe-se a conclusão recorrente de que a incapacidade de resposta institucional frente às demandas individuais leva os afetados a buscarem a via da mobilização social agrupada para fazerem-se ouvir pelos líderes do Processo. Encontramos tais conclusões em Kotler (2006), ao analisar o movimento dos Familiares de Detenidos-Desaparecidos de Tucumán; em Jelín e Azcarate (1991), com seu estudo sobre os movimentos surgidos a partir da segunda metade dos anos 1970; no estudo de Pereyra (2001) sobre o movimento dos Hijos de Desaparecidos; na análise de Alonso (2008) sobre movimentos de direitos humanos da Província de Santa Fé; em Rodríguez (2012), com seu estudo sobre os movimentos de Madres y Abuelas de la Plaza de Mayo; e no estudo de Mallimaci (2006) sobre os movimentos de direitos humanos na cidade de Buenos Aires.

Como a repressão na Argentina não se preocupava com a questão da legalidade, estando comprovada a existência de centros clandestinos de detenção (CONADEP, 1984), as respostas institucionais dadas aos familiares dos detidos e desaparecidos eram insuficientes ou, em grande parte dos casos, nulas (NOVARO; PALERMO, 2006). Com isso, a alternativa encontrada pelos familiares, observando ao longo do tempo a existência de outros casos similares, foi a da agrupação e mobilização social, na tentativa de mostrar a toda a sociedade argentina as violações cometidas 
pelo Processo, esperando assim conquistar a resposta governamental quanto ao destino de seus familiares.

Já no caso do Brasil, como visto anteriormente, o regime militar preocupava-se com uma aparência de legalidade visando sua legitimação, construindo um aparato institucional para a repressão e sua legitimação perante a população (PEREIRA, 2010). Assim, como grande parte dos casos de perseguição política se enquadrava nas leis que fundamentavam a doutrina de segurança nacional, a resposta institucional às demandas dos familiares e movimentos de direitos humanos se baseava no julgamento dos réus, absolvição ou condenação e posterior prisão, mostrando-se a preocupação com a aparência de legalidade (BARREIRA; GONÇALVES, 2010). Mesmo que as respostas institucionais não resolvessem o problema das violações de direitos humanos e da repressão, em certa medida mitigavam as possibilidades de acolhimento das demandas dos afetados e dos movimentos de direitos humanos para além do âmbito institucional, já que o regime legitimava a repressão por meio do emprego do processo jurídico - ainda que moldado aos interesses dos militares - para a apreciação dos casos de violação da Lei de Segurança Nacional (FERNANDES, 2010).

Em última instância, na Argentina a resposta institucional às demandas dos movimentos de direitos humanos era o silêncio, e no Brasil a resposta institucional era a jurídica, demonstrando que existiam regras para a repressão, baseadas nos interesses nacionais definidos pelo governo, e os acusados de violarem as regras eram julgados, absolvidos ou condenados e presos, sendo esta a tônica geral do processo - havendo casos de exceção - que focava na aparência de legalidade do regime militar brasileiro.

Desse modo, os afetados na Argentina buscaram a via da mobilização social agrupada para ganharem visibilidade social e assim forçar a resposta institucional, enquanto no Brasil os afetados recebiam respostas institucionais por meio do processo legal existente, entravando as possibilidades de expansão de suas demandas para o restante da sociedade, as quais deveriam então basear-se na oposição aos métodos repressivos do regime e à doutrina que os balizavam.

\subsubsection{Papel dos líderes do antigo regime na transição}

Com a análise desta variável procura-se observar como os recursos de poder detidos pelos líderes dos regimes militares foram empregados no processo de transição, conseguindo maior ou menor êxito no acolhimento de seus interesses na transição, principalmente no tocante às violações de direitos humanos e na condenação pública dos excessos cometidos durante os governos militares, 
e como a atuação dos líderes militares limitou ou fomentou a atuação dos movimentos de direitos humanos na sociedade.

Após a derrota na Guerra das Malvinas ${ }^{4}$ (1982) o regime militar argentino não conseguiu acordar ou impor um programa mínimo de transição. Em última instância, na transição política argentina dos anos 1980 não havia muito o que negociar, já que os recursos de poder detidos pelos líderes da junta militar eram escassos (NOVARO; PALERMO, 2006). Com isso, as demandas dos afetados pela violação dos direitos humanos durante o Processo passavam a fazer parte da pauta da transição, pois os militares não conseguiram isolá-las e deixá-las em segundo plano, como ocorrido no Brasil.

No caso brasileiro, o que observamos é a transição negociada, gradual e dialogada, entre os líderes do regime militar e os principais políticos civis, principalmente pela existência de um sistema político que permitia a oposição, cada vez mais liberalizada após a Lei de Anistia e a instalação de um sistema multipartidário, em que as violações de direitos humanos cederam espaço na pauta da transição para as questões relativas à retomada do processo democrático (QUEIROZ, 2012; VASCONCELOS, 2013). Isso foi possível, por um lado, graças aos recursos de poder ainda detidos pelos militares, que continuavam a influenciar politicamente e a deter prerrogativas incompatíveis com o regime democrático que se estabelecia (ZAVERUCHA, 2000) e, por outro lado, pelos anseios e aspirações dos principais líderes civis no processo de transição (BARREIRA; GONÇALVES, 2010), ao passo que a Lei de Anistia de 1979 havia mitigado as demandas por direitos humanos com seu intento de superar essa questão, passando a pautar a transição na democracia, deixando as demandas dos movimentos de direitos humanos em segundo plano (GONZÁLEZ, 1994).

Com isso, se na transição brasileira os militares tiveram papel preponderante, de negociação, observando-se por um lado concessões à oposição e por outro as afirmações autoritárias de privilégio executivo, na transição argentina os militares não gozavam de uma situação similar, estando enfraquecidos após a incapacidade de superação da crise econômica e o fracasso da empreitada militar da guerra contra os ingleses, com um papel muito mais de reação, abrindo o espaço para a contestação generalizada das políticas empregadas durante o regime, inclusive a das violações dos direitos humanos. Assim, a transição argentina abriu oportunidades para a atuação dos movimentos de direitos humanos no processo, enquanto a transição brasileira já

\footnotetext{
${ }^{4}$ Conflito travado entre a Argentina e a Grã-Bretanha pelo controle do arquipélago no Atlântico Sul, utilizado pelo governo do tenente-general Leopoldo Galtieri na tentativa de retomar a legitimidade do regime perante a população. Encerrou-se com a derrota argentina e a retirada do território do arquipélago após dois meses e meio de conflito (NOVARO; PALERMO, 2006).
} 
havia buscado a superação da questão com a Lei de Anistia, focando-se no âmbito do retorno democrático.

\subsubsection{Tratamento governamental aos movimentos de direitos humanos no final do regime autoritário}

Com esta variável, objetiva-se observar o impacto da forma como os regimes militares lidavam com os movimentos de direitos humanos, em seu período final, e o modo como as demandas desses movimentos eram acolhidas pelo restante da sociedade e como passaram a pautar, ou não, a agenda da transição. Nesse âmbito, é necessário ter em conta os elementos das variáveis anteriormente apresentadas, principalmente os recursos de poder possuídos pelos líderes dos regimes, bem como as respostas institucionais dadas às demandas por direitos humanos.

Mesmo cada vez mais próximo da derrocada, com perda crescente do apoio da sociedade, o regime militar argentino seguia reprimindo os movimentos de direitos humanos que, por sua vez, ganhavam mais proeminência que as demais organizações da sociedade - partidos políticos, igrejas, sindicatos, etc. (NOVARO; PALERMO, 2006). Da análise de uma mobilização feita na Plaza de Mayo, em dezembro de 1982, reunindo cerca de 80.000 pessoas, Novaro e Palermo (2010, p. 502) demonstram a ação da ala dura dos militares frente aos protestos cada vez maiores dos movimentos de direitos humanos: "la policía desató un impresionante operativo de represión, que provocó numerosas detenciones, heridos y un muerto”.

Já no caso brasileiro, com a transição pactuada, a democracia, a campanha pelas eleições diretas e os partidos políticos ganhavam maior destaque (VASCONCELOS, 2013). Como os militares haviam logrado pautar a transição em torno da democracia, o espaço conquistado pelos movimentos de direitos humanos era pequeno, se comparado ao caso argentino, e as grandes manifestações pouco antes do fim do regime militar demandavam eleições diretas para a presidência da república (BARREIRA; GONÇALVES, 2010). Assim, o tratamento governamental aos movimentos de direitos humanos foi de preterição, preocupando-se com o concernente à democracia. Em suma, com a campanha das Diretas Já.

Na Argentina os movimentos de direitos humanos cresciam, ao passo que as atrocidades da repressão do regime militar vinham à tona. A repressão das manifestações nos anos de 1982 e 1983 apenas colaborou com o arraigamento das demandas desses movimentos no seio da sociedade, enquanto, no Brasil, os movimentos de direitos humanos cada vez mais perdiam espaço público, principalmente pelo fato de o regime militar ter-se preocupado em organizar a agenda da transição, 
liberalizando crescentemente a arena política, tornando-a a principal na transição, respondendo com a preterição às demandas dos movimentos de direitos humanos.

\subsubsection{Participação da sociedade no final do regime}

Na apreciação desta variável o objetivo é analisar a participação da sociedade no final dos regimes militares, observando se essa participação supriu em parte os anseios e demandas dos movimentos sociais, ou se manteve a lógica de incapacidade das respostas governamentais aos anseios da sociedade mobilizada, bem como analisar se as demandas dos movimentos de direitos humanos se enquadram nesse cenário.

O final do regime militar argentino não se deu pela mobilização popular, sendo mais um efeito da crise interna do regime com o fracasso na Guerra das Malvinas. A direção partidária apenas se adequou às circunstâncias. A mobilização popular somente acelerou um processo em curso, fornecendo mais recursos de poder aos líderes partidários que seriam os futuros líderes políticos do governo democrático (NOVARO; PALERMO, 2006).

Rampinelli (2012) faz uma ressalva quanto à relevância da constante atuação dos movimentos de direitos humanos, bem como das dissensões entre os próprios militares, para a derrocada do Processo; contudo, posiciona a derrota na Guerra das Malvinas como um fenômeno crucial para a transição. Assim, a crescente presença dos movimentos de direitos humanos nas mobilizações do final do regime fez com que suas demandas ganhassem certa proeminência social, todavia, necessitando serem consideradas pelas lideranças partidárias ${ }^{5}$, que passavam a ser atores centrais nesse contexto.

No caso brasileiro, o final do regime deu-se com ampla mobilização popular pela transição democrática, com foco na participação direta da sociedade nesse processo (campanha Diretas Já), mesmo que tenha resultado num pacto negociado “por cima” (BARREIRA; GONÇALVES, 2010).

O que buscamos ressaltar é a participação da sociedade na transição, e como o legado da Lei de Anistia de 1979 fez com que a questão dos direitos humanos fosse superada em prol da mobilização pelo retorno democrático. Em suma, "os direitos humanos foram e ainda são vistos marginalmente, como coisa de quem está fora da lei e da ordem pública e, definitivamente, esse é um resquício de uma nação que optou por esconder verdades e maquiar fatos históricos de forma ideológica” (QUEIROZ, 2012, p. 229). Assim como na Argentina, no Brasil também foram as

\footnotetext{
${ }^{5}$ Um caso exemplar é o do primeiro presidente eleito no período pós-Processo, Raúl Alfonsín, ativista de direitos humanos durante a ditadura, que tornou a pauta das violações de direitos humanos pelo regime da junta militar uma das principais de sua campanha para as eleições de 1983 (NOVARO; PALERMO, 2006).
} 
lideranças partidárias que capitalizaram os efeitos das mobilizações sociais. Contudo, as demandas de maior proeminência no cenário da transição diziam respeito à democracia, ao processo político e às liberdades civis e políticas.

Nesse sentido, no final do regime militar argentino a participação da sociedade não foi um elemento central, pautando-se mais pela adequação às circunstâncias criadas pela própria crise interna do regime. Já no final do regime militar brasileiro, a participação da sociedade foi intensa, também por meio de circunstâncias criadas pelo regime militar. Contudo, nesse caso o regime militar havia sido o artífice do modelo político multipartidário vigente, apenas se equivocando quanto à amplitude da participação popular. Todavia, como os líderes militares ainda possuíam recursos de poder, puderam negociar a transição, tendo a primeira eleição sido realizada no Colégio Eleitoral $^{6}$, e não de forma direta. Com isso, os militares brasileiros lograram mitigar a participação dos movimentos de direitos humanos e suas demandas na pauta da transição.

\subsection{FATORES ORGANIZACIONAIS}

A análise deste conjunto de fatores visa focar na dinâmica interna dos movimentos de direitos humanos nos dois países, apreciando algumas diferenças que possam explicar as formas distintas como as demandas de tais movimentos foram acolhidas pela sociedade no período de transição.

Parte-se de uma perspectiva de movimentos sociais que buscam o estabelecimento de um sistema de valores fundamentais baseados na defesa da vida, da verdade e da justiça, preocupados com a criação de uma identidade comum, capaz de articular práticas de protesto social, e de que tais práticas logrem transcender o âmbito interno dos movimentos (ALONSO, 2008; CUETO RÚA, 2010; RODRÍGUEZ, 2012).

Ademais, buscando estabelecer uma diferenciação entre movimentos de direitos humanos surgidos como consequência dos regimes militares argentino e brasileiro e as formas tradicionais de contestação política e pública, parte-se de uma abordagem que leva em conta o contexto de crise social e institucional de um país, possibilitando a compreensão dos movimentos sociais como uma nova forma de atuação política. "Partiendo de esta cuestión es posible afirmar que los movimientos sociales surgen en momentos en que los canales tradicionales por los que se rigen las sociedades modernas están clausurados o han entrado en crisis” (KOTLER, 2006, p. 28).

\footnotetext{
${ }^{6}$ Formado pelo Congresso Nacional e representantes das assembleias legislativas. Em 15 de janeiro de 1985 elegeu Tancredo Neves para a Presidência da República, tendo derrotado o candidato Paulo Maluf por 480 votos contra 180 , com 26 abstenções (PEREIRA, 2010).
} 


\subsubsection{Transposição de demandas privadas ao espaço público}

Esta variável é considerada no afã de analisar o modo como os movimentos de direitos humanos de afetados pela repressão dos regimes militares lograram transpor seus dramas, pessoais e familiares, do âmbito privado para o público, tornando-os demandas da sociedade aos governantes.

No caso argentino, os movimentos de afetados lograram transpor um drama pessoal para uma matéria que deveria ser canalizada e atendida pelo conjunto da sociedade. Nesse sentido, os atos públicos, as saídas à rua, os jejuns e o uso dos panos brancos foram estratégias que excederam o âmbito privado, transpassaram-no e ocuparam o espaço público, conseguindo ter presença nele (KOTLER, 2006; PEREYRA, 2001; ALONSO, 2008; CUETO RÚA, 2010; RODRÍGUEZ, 2012).

É nesse âmbito que Novaro e Palermo (2006) destacam a centralidade que os movimentos de afetados passaram a ocupar no comportamento de outros atores sociais, como os meios de comunicação e os relativos à arena cultural, sendo incorporados ao processo de transição que esteve, em grande medida, centrada na denúncia e na reparação da violação de direitos que era o escopo básico dos movimentos de afetados: "Ni los partidos, ni los sindicatos, ni mucho menos los actos oficiales lograrían destronar del sitial de absoluta preeminencia que habían pasado a ocupar en la atención del público las rondas de las Madres, los inhumaciones en los cementerios, las denuncias judiciales.” (NOVARO; PALERMO, 2006, p. 509).

No caso brasileiro, a pauta dos direitos humanos não mobilizava a sociedade e as pessoas evitavam o assunto. Como visto anteriormente, a aprovação da Lei de Anistia contribuiu, de certa forma, para o estabelecimento de um censo comum de que os efeitos nocivos da repressão do regime haviam sido superados com a anistia de todos os presos e exilados políticos (GONÇALVES, 2006). Com isso, os movimentos de direitos humanos perderam espaço público e passaram por uma reformulação, focando nas condições de tratamento dadas aos presos comuns e outras formas de violações de direitos humanos (GONZÁLEZ, 1994).

Essa incapacidade de transpor as demandas privadas ao espaço público revela uma debilidade dos movimentos de direitos humanos no Brasil, não conseguindo superar o pacto negociado pelo regime militar em torno da mitigação das violações de direitos humanos para a transição política. Um caso exemplar dessa problemática, apresentado por Queiroz (2012, p. 234), é o do Movimento Nacional de Direitos Humanos (MNDH), que, mesmo tendo iniciado suas atividades na esfera contestatória das violações de direitos humanos pelo regime militar, em suas “frentes de lutas visíveis” não priorizavam esses aspectos. O MNDH “iniciou sua atuação com o combate à violência, à impunidade, às arbitrariedades, à tortura, sem, contudo, estabelecer uma ligação com os horrores do que foi a ditadura militar” (QUEIROZ, 2012). 
Assim, comparando-se os movimentos de direitos humanos na Argentina e no Brasil, temse que os primeiros conseguiram transpor as demandas privadas ao espaço público, constituindo-se em novas formas de contestação pública, e os segundos não conseguiram alcançar tal patamar. Os movimentos de direitos humanos argentinos conseguiram uma transposição efetiva de suas demandas ao espaço público, enquanto os movimentos de direitos humanos brasileiros conseguiram apenas uma transposição insuficiente, preterida pelo debate acerca da transição política.

\subsubsection{Estruturação prévia dos movimentos}

A análise desta variável centra-se na consideração da articulação e desenvolvimento histórico de movimentos de direitos humanos capazes de resistirem aos ciclos de oportunidades enfrentados desde seu surgimento, com avanços e retrocessos passíveis de influenciar diretamente em sua atuação, como as variáveis até aqui estudadas.

No caso argentino, como ressaltam Novaro e Palermo (2006, p. 464), os movimentos de afetados pelo regime se fortaleciam por existirem previamente. Neste contexto, é importante destacar o fato de os movimentos estabelecidos como consequência dos governos de 1976-83 terem surgido já em 1977. E, quanto ao período de transição para o regime democrático, evidencia-se a manutenção dos movimentos surgidos durante o regime militar, que "fizeram a diferença em um contexto de transição favorável às políticas de revisão do passado ${ }^{7}$ e foram atores responsáveis por manter o tema na agenda pública durante os períodos de retrocesso dessas iniciativas” (VASCONCELOS, 2013, p. 160).

Já no caso brasileiro a estruturação dos movimentos de afetados passa a ter relevância no quadro analisado apenas na segunda metade da década de 1970 - sendo que o regime militar foi instalado em 1964 - (BARREIRA; GONÇALVES, 2010), justamente no momento em que se debate a formulação e aprovação da Lei de Anistia, o que acaba minando as possibilidades de discussão posterior das violações no caso brasileiro (QUEIROZ, 2012).

Com isso, a manutenção dos reclamos dos movimentos de direitos humanos na Argentina pode ser atribuída à forma como esses movimentos se estruturaram e mantiveram ao longo do tempo, principalmente por sua estruturação ser repentina, surgindo espontaneamente pouco tempo após à instalação do regime militar, como uma reação à ineficiência institucional em atender as demandas individuais, como analisado previamente. No caso brasileiro, porém, os movimentos de

\footnotetext{
${ }^{7}$ Como visto previamente, o tema das violações de direitos humanos se tornou pauta importante do debate político nas eleições de 1983, principalmente pela atuação de ativistas e ex-ativistas dos movimentos de direitos humanos no processo eleitoral, como o próprio presidente eleito, Raúl Alfonsín.
} 
direitos humanos tiveram uma estruturação tardia, intensificando sua atuação justamente no momento em que o regime promovia o debate em torno da anistia que, com a aprovação da Lei de Anistia, minou oportunidades de atuação desses movimentos. Assim, na transição do regime militar para o civil, os movimentos de direitos humanos ficaram em segundo plano, perdendo espaço para as demandas por liberdades civis e políticas.

Assim, podemos condensar os argumentos apresentados para a explicação das diferenças entre os movimentos de direitos humanos na Argentina e no Brasil na seguinte tabela:

Tabela 2. Variáveis com maior poder explicativo

\begin{tabular}{|c|c|c|c|}
\hline FATORES & VARIÁVEL & ARGENTINA & BRASIL \\
\hline $\begin{array}{l}\text { 1.1 Fatores } \\
\text { conjunturais }\end{array}$ & 1.1.1 Eventos exógenos & Mobilização & Inércia \\
\hline \multirow{7}{*}{$\begin{array}{l}1.2 \text { Fatores } \\
\text { estruturais }\end{array}$} & $\begin{array}{l}\text { 1.2.1 Estratégia do regime contra } \\
\text { o comunismo }\end{array}$ & Combate & Prevenção \\
\hline & $\begin{array}{c}\text { 1.2.2 Processo de modernização } \\
\text { social e cultural }\end{array}$ & Superficial & Dinâmico \\
\hline & 1.2.3 Mecanismos de censura & Autocensura & Institucionalização \\
\hline & $\begin{array}{c}\text { 1.2.4 Resposta institucional às } \\
\text { demandas dos movimentos de } \\
\text { direitos humanos }\end{array}$ & Silêncio & Jurídica \\
\hline & $\begin{array}{l}\text { 1.2.5 Papel dos líderes do antigo } \\
\text { regime na transição }\end{array}$ & Reação & Negociação \\
\hline & $\begin{array}{c}\text { 1.2.6 Tratamento governamental } \\
\text { aos movimentos de direitos } \\
\text { humanos no final do regime } \\
\text { autoritário }\end{array}$ & Repressão & Preterição \\
\hline & $\begin{array}{c}\text { 1.2.7 Participação da sociedade } \\
\text { no final do regime }\end{array}$ & Adequação & Intensa \\
\hline \multirow{2}{*}{$\begin{array}{c}1.3 \text { Fatores } \\
\text { organizacionais }\end{array}$} & $\begin{array}{l}\text { 1.3.1 Transposição de demandas } \\
\text { privadas ao espaço público }\end{array}$ & Efetiva & Insuficiente \\
\hline & $\begin{array}{c}\text { 1.3.2 Estruturação prévia dos } \\
\text { movimentos }\end{array}$ & Repentina & Tardia \\
\hline
\end{tabular}

Fonte: elaboração dos autores

\section{CONSIDERAÇÕES FINAIS}

Para que determinássemos uma explicação que permitisse alcançar os objetivos traçados neste trabalho, vimos que era necessário que na análise dos dados fossem estabelecidas variáveis de comparação entre ambos os países, as quais, por sua vez, conjugaram-se em três categorias de fatores explicativos. Da relação entre as categorias de fatores e as variáveis resultaram as explicações para as diferenças de atuação dos movimentos de direitos humanos nos casos 
estudados. Dessa conjugação de fatores, apuramos que o processo histórico dos regimes autoritários tem um peso importante na análise da atuação dos movimentos sociais em ambos os países.

Dentro desse processo, destaca-se a centralidade de eventos conjunturais que preponderaram nas explicações encontradas na pesquisa. Quanto ao florescimento da mobilização social na Argentina, é recorrente a atribuição de papel central à visita da Comissão Interamericana de Direitos Humanos ao País em 1979. E no que diz respeito à inércia brasileira, a explicação mais recorrente refere-se à aprovação da Lei de Anistia em 1979.

Todavia, argumentamos que ambas as categorias de fatores careceriam de força explicativa se estivessem desvinculadas da apreciação dos fatores organizacionais, pois apenas movimentos estruturados previamente, capazes de atuarem quando do surgimento de oportunidades conjunturais, capazes de resistirem à repressão permanente do regime, capazes de se integrarem às demandas da sociedade de mudança quando do aprofundamento do processo de derrocada do regime, podem ser considerados movimentos capazes de terem maior espaço público no momento da transição.

Constatamos que, no tocante aos fatores conjunturais, os eventos exógenos influenciaram na mobilização na Argentina e na inércia no caso brasileiro. No que diz respeito aos fatores estruturais percebemos que, no caso argentino, o modo de atuação do regime autoritário frente à sociedade, em geral, e aos movimentos de direitos humanos, em particular, priorizando elementos repressivos e violentos, culminou em um maior ativismo e participação dos movimentos de direitos humanos na contestação do regime. Já no caso brasileiro, o regime buscou legitimar-se frente à sociedade, priorizando a institucionalização da sua atuação, dando-lhe uma faceta de legalidade. Quanto aos fatores organizacionais, identificamos que no caso argentino os movimentos de direitos humanos conseguiram, com uma mobilização repentina, traduzirem suas demandas internas em demandas da sociedade, enquanto no caso brasileiro os movimentos de direitos humanos, mobilizados tardiamente, não lograram a transposição social de suas demandas.

\section{REFERÊNCIAS}

ALONSO, Luciano. El surgimiento del movimiento argentino por los derechos humanos en perspectiva comparada. In: Páginas: Revista digital de la escuela de historia - UNR, año $1, \mathrm{n}^{\circ} 1$, Rosario, 2008, p. 87-109.

BARREIRA, Irlys; GONÇALVES, Danyelle Nilin. Anistiar ou esquecer? Direitos humanos e os perseguidos políticos no Brasil. In: O público e o privado, n. 15 - Janeiro/Junho, 2010, p. 71-80.

BRESSER-PEREIRA, Luiz C. Os dois congelamentos de preços no Brasil. In: Revista de Economia Política, Vol. 8, nº. 4, outubro-dezembro/1988. p. 48-66. 
COMBLIN, Joseph. A ideologia da Segurança Nacional: o poder militar na América Latina. Rio de Janeiro: Civilização Brasileira, 1978.

CONADEP. Nunca Mais: informe da Comissão Nacional sobre o Desaparecimento de Pessoas na Argentina, presidida por Ernesto Sábato. Tradução Roberto Mara. Porto Alegre: L\&PM Editores, 1984.

CUETO RÚA, Santiago. Hijos de víctimas del terrorismo de Estado: Justicia, identidad y memoria en el movimiento de derechos humanos en Argentina, 1995-2008. In: Historia critica, n. 40, Bogotá, enero-abril 2010, p. 122-45.

FERNANDES, Pádua. Ditadura militar na América Latina e o Sistema Interamericano de Direitos Humanos: (in)justiça de transição no Brasil e na Argentina. In: Congreso Internacional 1810-2010: 200 años de Iberoamérica, 2010, p. 1674-92.

GALLO, Carlos Artur. O direito à memória e à verdade no Brasil pós-ditadura civil-militar. In: Revista Brasileira de História \& Ciências Sociais, Vol. 2 N 4, Dezembro de 2010, p. 134-45.

GONÇALVES, Danyelle Nilin. O Preço do passado: Anistia e reparação de perseguidos políticos no Brasil. 2006, 253 f. Tese de Doutorado (Programa de Pós-Graduação em Sociologia da Universidade Federal do Ceará), Fortaleza, 2006.

GONZÁLEZ, Rodrigo Stumpf. Direitos Humanos e Democracia na transição brasileira: OAB, CNBB e Anistia Internacional. 1994, 222f. Dissertação de mestrado (Programa de Pós-Graduação em Ciência Política da Universidade Federal do Rio Grande do Sul), Porto Alegre, 1994.

JELIN, Elizabeth; AZCÁRATE, Pablo. Memoria y política: movimientos de derechos humanos y construcción democrática. In: América Latina Hoy. Universidad de Salamanca, n. 1, julio, 1991, p. 29-38.

KOTLER, Rubén Isidoro. Los movimientos sociales: forma de resistencia a la dictadura. Madres de Detenidos-Desaparecidos de Tucumán. In: Cuadernos de Historia Oral, n. 7, Universidad de Buenos Aires, 2006, 98 p.

MALLIMACI, Fortunato. La dictadura argentina: terrorismo de Estado e imaginario de la muerte. Ponencia presentada al Instituto de Historia Social Argentina de la Universidad de Buenos Aires, 2006.

NOVARO, Marcos; PALERMO, Vicente. La dictadura militar 1976-1983: del golpe de Estado a la restauración democrática. Buenos Aires: Paidós, 2006.

PEREIRA, Anthony W. Ditadura e repressão: o autoritarismo e o estado de direito no Brasil, no Chile e na Argentina. São Paulo: Paz e Terra, 2010.

PEREYRA, Sebastián. Las protestas de derechos humanos en la Argentina de la democrática 19891998. In: Meeting of the Latin American Studies Association, Washington DC, September 6-8, 2001.

QUEIROZ, Rosiana. Direito à memória, à verdade e à justiça. In: MOVIMENTO NACIONAL DE DIREITOS HUMANOS et al. Direitos Humanos no Brasil 3: diagnósticos e perspectivas. Passo Fundo: IFIBE, 2012, p. 227-38. 
RAMPINELLI, Waldir José. O terrorismo de Estado na Argentina. In: REBELA, v. 1, n. 3, fev. 2012, p. 356-62.

RODRÍGUEZ, Vera Sofía. Movimientos sociales, territorio e identidad: el movimiento de Madres y Abuelas de Plaza de Mayo. In: Geograficando, año 8 no. 8, 2012, p. 213-32.

SAMWAYS, Daniel Trevisan. Censura à imprensa e a busca de legitimidade no regime militar. In: VESTÍGIOS DO PASSADO: a história e suas fontes. IX Encontro Estadual de História (Associação Nacional de História - Seção Rio Grande do Sul). 2008. Disponível em: <http://eeh2008.anpuhrs.org.br/resources/content/anais/1212349634_ARQUIVO_Censuraaimprensaeabuscadelegitimidad enoregimemilitar.pdf $>$. Acesso em: 8 ago. 2014.

STEINKE, Sabrina. Apontamentos sobre a transição democrática argentina. In: Anais do XXVI Simpósio Nacional de História - ANPUH , São Paulo, julho 2011.

VASCONCELOS, Daniela. Autoritarismo, direitos humanos e redemocratização: uma análise comparativa da justiça de transição no Brasil e na Argentina. In: Revista Andina de Estudios Políticos. Vol. III, n. 1, p. 134-65.

VERBITSKY, Horacio. Tres décadas de democracia. In: CENTRO DE ESTUDIOS LEGALES Y SOCIALES. Derechos Humanos en Argentina: Informe 2013. Buenos Aires: Siglo Veintiuno Editores, 2013, p. 23-49.

ZAVERUCHA, Jorge. Frágil democracia: Collor, Itamar, FHC e os militares (1990-1998). Rio de Janeiro: Civilização Brasileira, 2000.

\section{SOCIAL MOVEMENTS OF HUMAN RIGHTS, AUTHORITARIAN REGIMES AND TRANSITION: COMPARATIVE ANALYSIS BRAZIL AND ARGENTINA}

ABSTRACT: This article seeks to analyze the factors that influenced the actions of human rights social movements during the authoritarian regimes, as well as in the process of democratic transition in Brazil and Argentina. At the same time, we seek to answer the following question: Why in Argentina there was a great mobilization of social movements struggling for memory and justice related to the regime of the military government (1976-1983), and in Brazil there was not much to the military government of 1964-1985? To establish an explanation that would help us to achieve the objectives outlined in this paper, we saw that it was necessary to sustain the data by combining three categories of explanatory factors, which in turn would facilitate the establishment of comparison variables between both countries. From this combination of factors, we found that the historical process of authoritarian regimes is an important factor to analyze the activity of social movements in both countries. To collect data that supports our comparative basis, we appeal to the literature review.

KEYWORDS: Argentina. Authoritarian regimes. Brazil. Social movements. 